\title{
Direct measurements of the effect of biomass burning over the Amazon on the atmospheric temperature profile
}

\author{
A. Davidi ${ }^{1}$, I. Koren ${ }^{1}$, and L. Remer ${ }^{2}$ \\ ${ }^{1}$ Department of Environmental Sciences, Weizmann Institute, Rehovot, Israel \\ ${ }^{2}$ NASA Goddard Space Flight Center, Greenbelt, Maryland, USA
}

Received: 6 April 2009 - Published in Atmos. Chem. Phys. Discuss.: 15 May 2009

Revised: 16 October 2009 - Accepted: 19 October 2009 - Published: 3 November 2009

\begin{abstract}
Aerosols suspended in the atmosphere interact with solar radiation and clouds, thus change the radiation energy fluxes in the atmospheric column. In this paper we measure changes in the atmospheric temperature profile as a function of the smoke loading and the cloudiness, over the Amazon basin, during the dry seasons (August and September) of 2005-2008. We show that as the aerosol optical depth (AOD) increases from 0.02 to a value of $\sim 0.6$, there is a decrease of $\sim 4^{\circ} \mathrm{C}$ at $1000 \mathrm{hPa}$, and an increase of $\sim 1.5^{\circ} \mathrm{C}$ at $850 \mathrm{hPa}$. The warming of the aerosol layer at $850 \mathrm{hPa}$ is likely due to aerosol absorption when the particles are exposed to direct illumination by the sun. The large values of cooling in the lower layers could be explained by a combination of aerosol extinction of the solar flux in the layers aloft together with an aerosol-induced increase of cloud cover which shade the lower atmosphere. We estimate that the increase in cloud fraction due to aerosol contributes about half of the observed cooling in the lower layers.
\end{abstract}

\section{Introduction}

Aerosol effects on clouds contribute the largest uncertainties in estimating the anthropogenic role in climate change (Forster et al., 2007; Stevens and Feingold, 2009, and references therein). Aerosols can affect cloud properties through two separate pathways, the microphysical and the radiative (Kaufman and Koren, 2006; Koren et al., 2008). The first pathway follows aerosol-induced changes to the cloud condensation nuclei (CCN) and ice nuclei (IN) concentrations and distributions, thus changing the microphysical properties of the cloud and stimulating related processes (Twomey, 1977; Rosenfeld, 2000; Albrecht, 1989; Koren et al., 2005;

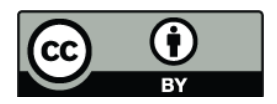

Correspondence to: A. Davidi (amit.davidi@weizmann.ac.il) see also a review by Lohmann and Feichter, 2005). The second pathway originates in the optical properties of the aerosols. Aerosols scatter and absorb solar radiation, thus reducing the amount of radiation reaching the ground, which cools the surface (Hansen et al., 1997; Ackerman et al., 2000). This affects the energy balance of the surface, decreasing surface latent and sensible heat fluxes, which inhibits cloud formation. In addition, by absorbing solar radiation, biomass burning aerosols heat the atmospheric layer in which they are located. Warming the layer may reduce convective cloudiness, which is the dominant cloud type in our region, due to: (I) reduction of local relative humidity; (II) creating a more stable atmosphere and producing less convection; therefore, a cooler surface and more stable atmosphere may (III) reduce fluxes of moisture from the surface (evaporation and evapotranspiration) to the atmosphere (Koren et al., 2004; Feingold et al., 2005). The reduction of moisture fluxes is also due to the closure of vegetation's stomata, in response to high smoke loading, as suggested by Andreae et al. (2002). Process (III) is of great importance in the Amazonian atmosphere, where $\sim 50 \%$ of the available atmospheric moisture comes from evapotranspiration of the canopy (Salati, 1987).

The two pathway conceptual model was suggested by Koren et al. (2008) who showed the relationship between cloud properties and aerosol loading. Furthermore, a large body of observational evidence supports the fundamentals of the microphysical pathway (Jiang and Feingold, 2006; Andreae and Rosenfeld, 2008). However, the fundamentals of the second pathway, that aerosols are heating the atmosphere and cooling the surface, are based on radiative transfer calculations. There have been no direct measurements, that the authors aware of, of aerosol heating or cooling the atmospheric column, on a regional and seasonal basis.

In this paper we directly measure the change in atmospheric temperature profile over the Amazon basin in the presence of absorbing aerosols emitted from biomass

Published by Copernicus Publications on behalf of the European Geosciences Union. 


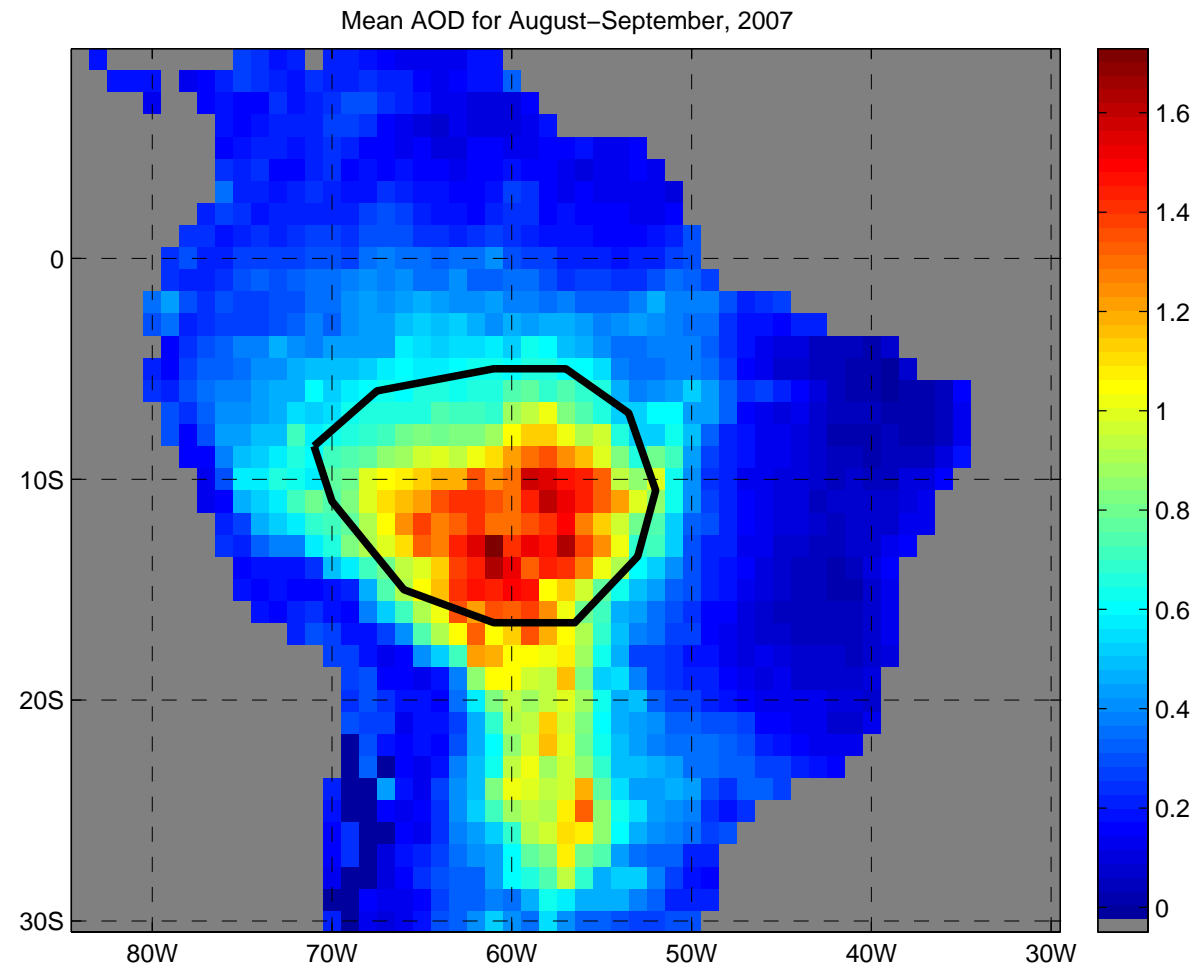

Fig. 1. Mean AOD values for the region analyzed in this work. The enclosed region (black line) encompasses $\sim 2 \times 10^{6} \mathrm{~km}{ }^{2}$. The AOD data were taken from MODIS retrievals, on a daily $1^{\circ}$ grid.

burning during the dry seasons (August and September) of 2005-2008. Apart from appreciating the Amazon as an important place, there are a few good reasons to study the effect of smoke on clouds and the atmospheric temperature profile over the Amazon:

1. During the dry season the ITCZ moves north and the study area is under an anticyclonic flow and a subsidence zone with very little meteorology variance (e.g. Nobre et al., 1998).

2. The fires during the Amazonian dry season are anthropogenic and their location depends on the farmers, the farm location and on law enforcement. Therefore, the source distribution does not depend on the regional meteorology. The smoke will be advected by the prevailing wind, which is mostly easterly in the east and central Amazon turning northerly in the western part of the basin when flow is blocked by the Andes.

The atmospheric temperature profile is measured with the Atmospheric Infra-Red Sounder (AIRS), on Aqua (Aumann et al., 2003). AIRS is a high spectral resolution infrared sounder, which is designed to provide atmospheric temperature and water vapor profiles. AIRS temperature retrieval has been validated in various campaigns that include different geophysical conditions: polar, non-polar, day, night, land, and ocean (Olsen et al., 2007, and references therein). In particular, the AIRS temperature profile over the Amazon basin, during September-October, was shown to have an RMS (root mean square) of about $1-2 \mathrm{~K}$ at pressure levels above $900 \mathrm{hPa}$ and an RMS of up to $3 \mathrm{~K}$ below $900 \mathrm{hPa}$ (de Souza et al., 2005). Another campaign in Natal/Brazil showed that the temperature retrieval RMS was about $1 \mathrm{~K}$ (de Souza et al., 2006). Clouds were shown to have only a minor effect on both the AIRS temperature profile (Susskind et al., 2006; Tobin et al., 2006) and the surface air temperature (Gao et al., 2008). As far as we know, there has been no publication on the effect of smoke - or aerosols in general - on the temperature retrieval. However, the works done by de Souza et al. $(2005,2006)$ in Brazil and Gao et al. (2008) in China may serve as an indication for the performance of AIRS temperature retrievals in hazy conditions. All the above mentioned validations were done with radiosondes; however one must keep in mind that the AIRS footprint is $45 \times 45 \mathrm{~km}$ at nadir, while radiosondes measure one point's profile, therefore the above RMS values are upper bounds for the true errors (Tobin et al., 2006). In addition, several studies showed that assimilation of AIRS temperature data can improve forecasting (Reale et al., 2008; Freitas et al., 2007); these may further support the validity of the retrieval. 


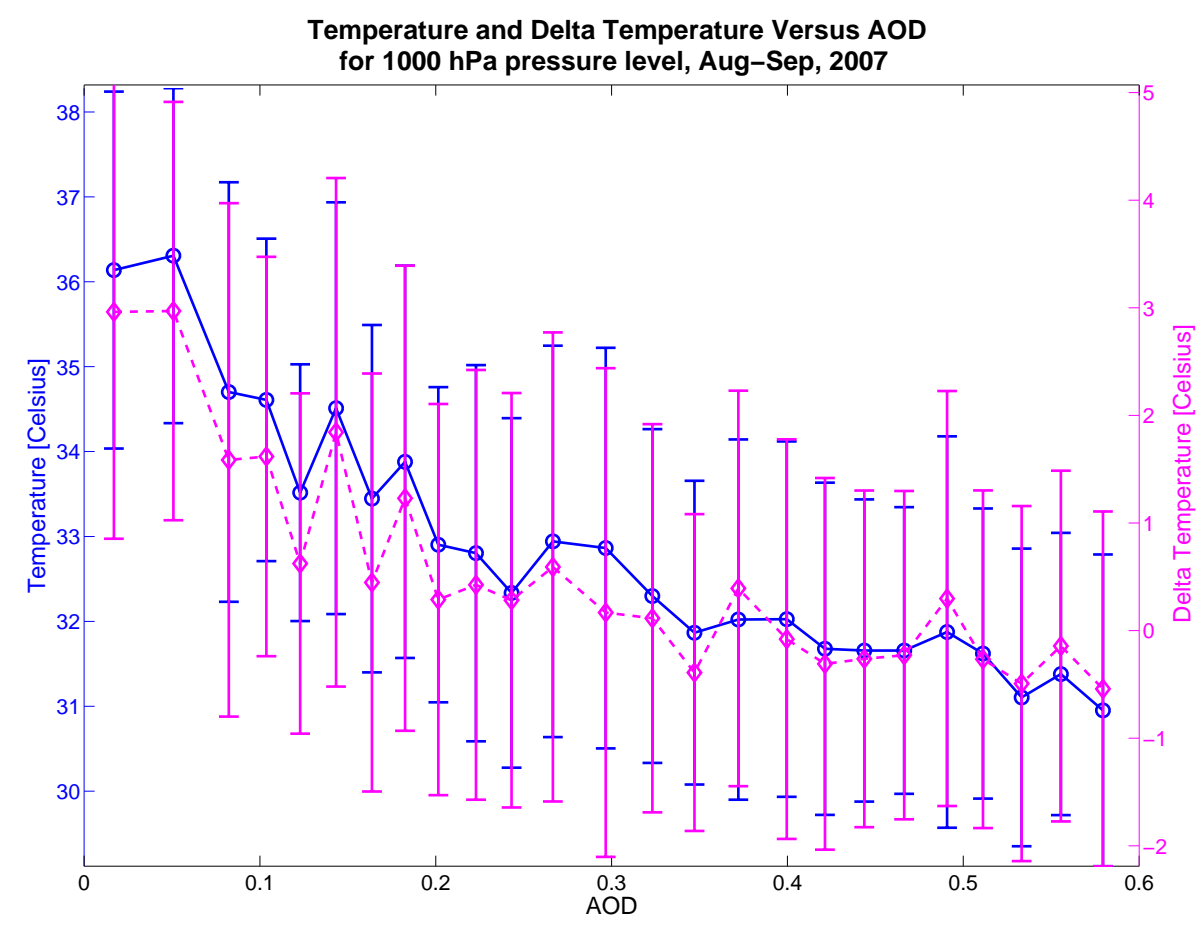

Fig. 2. Scatter plots of temperature ( $T$, blue line) and $\Delta T$ (magenta dashed line) vs. AOD, for the $1000 \mathrm{hPa}$ pressure level, of AugustSeptember 2007. $\Delta T$ is the difference in the local temperature less the spatial mean of each day, as defined in the text.

\section{Methodology}

The analyzed region over the Amazon basin was chosen to include the most polluted areas, while staying in a relatively small region (see Fig. 1). Also, to take advantage of the stable synoptic high pressure system (Nobre et al., 1998) without the complications of local geographically induced circulations, care was taken to not include the Andes and to be sufficiently far from the seashores (The area encompasses $\sim 2 \times 10^{6} \mathrm{~km}^{2}$ ).

We focus on the height of the biomass burning season, August and September, for the years 2005-2008. Aerosol optical depth (AOD) data were taken from the Moderate Resolution Imaging Spectroradiometer (MODIS) retrievals (Remer et al., 2008; Levy et al., 2007). We use Collection 5, Level 3,1-degree, daily data, and unless specified, all AOD is at $550 \mathrm{~nm}$. Atmospheric temperature profiles are retrieved from the Atmospheric Infra-Red Sounder (AIRS) (Aumann et al., 2003). We use Daily Global Level 3 products (1-degree resolution). Both MODIS and AIRS fly on the Aqua platform $(\sim 01: 30$ p.m. LT). In addition, we use total attenuated backscatter (at $532 \mathrm{~nm}$ ) images from Cloud-Aerosol Lidar with Orthogonal Polarization (CALIOP), on Calipso, in order to estimate the smoke layer height (Winker et al., 2003).

We have analyzed the AIRS retrieved temperatures at 4 altitude levels: 1000, 925, 850, and $700 \mathrm{hPa}$. Occasionally AIRS retrievals produce unphysical spikes in the temperature fields of a particular pressure level. We filtered out pixels in which the temperature difference between the pixel in question and its neighbors exceeded $20^{\circ} \mathrm{C}$. This eliminated about $0.5 \%$ of the data. The data were sorted according to AOD and binned into $\sim 25$ bins with equal number of samples in each bin to maintain similar temperature variances. This way any change in the variances (and hence in the standard deviation) could not be directly attributed to sample size. A scatter plot of the mean temperature of each bin versus the mean AOD of each bin was plotted. An estimation of the error was calculated from the standard deviation in each bin. To minimize cloud contamination, the AOD values were restricted to 0.6 and below (Brennan et al., 2005).

Since we want to focus on the aerosol regional effect, we first examine the variance in the temperature $(T)$ due to daily meteorological changes, using the following scheme. For a specific day and pressure level, the spatial mean temperature (denoted $\langle T\rangle_{\text {area }}$ ) was calculated. Then, this mean was subtracted from each temperature in the corresponding day and pressure level. Repeating this procedure for all days and pressure levels results with a $\Delta T$, which is defined as:

$\Delta T$ (location, day, press.) $\equiv T$ (location, day, press.)

$-\langle T\rangle_{\text {area }}$ (day, press.)

Plotting $\Delta T$ versus AOD will show a functional relationship between temperature and aerosols, even if there are day-today variations in the regional temperature. Figure 2 shows both $\Delta T$ and $T$ versus AOD, for pressure level $1000 \mathrm{hPa}$. The close agreement between $\Delta T$ and $T$ is an indication for 


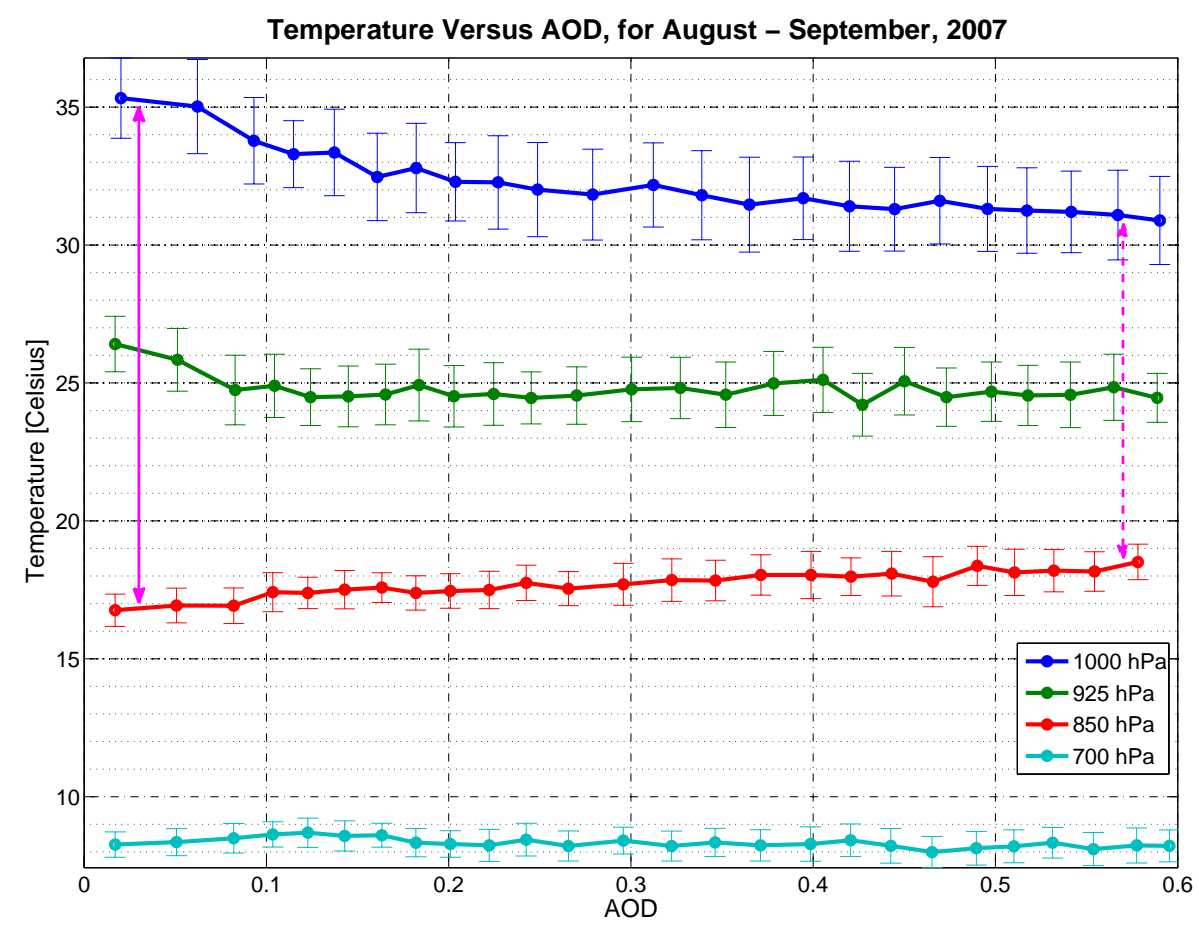

Fig. 3. Temperature vs. AOD, at four atmospheric pressure levels: $1000 \mathrm{hPa}$ (blue), $925 \mathrm{hPa}$ (green), $850 \mathrm{hPa}$ (red), and $700 \mathrm{hPa}$ (cyan), for the months August-September 2007. Each point represents a mean temperature for a particular AOD bin, and error bars are the standard deviation in each bin. The data consists of AIRS temperature profiles collocated with MODIS retrievals of AOD, on a daily $1^{\circ}$ grid. The straight and dashed magenta arrows represent the atmospheric stability (between 1000 and $850 \mathrm{hPa}$ ) in clean and hazy conditions, respectively. Note the cooling near the surface $(1000 \mathrm{hPa}$, blue) and the heating at $850 \mathrm{hPa}$ (red), as well as a decrease in atmospheric stability as the AOD increases.

the stability of the meteorology during the period analyzed in this work. We note that the other pressure levels (i.e. 925, 850 , and $700 \mathrm{hPa}$ ) show similar agreement. Because no significance differences are observed, further analysis is done with the "absolute" temperature $(T)$, which will be more visually instructive later on.

\section{Results}

Figure 3 shows the binned scatter plot of the temperature versus AOD of the 4 pressure levels, for the months AugustSeptember 2007. As the AOD increases from the lowest average value of 0.02 to 0.6 , there is a decrease of $\sim 4^{\circ} \mathrm{C}$ at $1000 \mathrm{hPa}$ (blue curve), an increase of $\sim 1.5^{\circ} \mathrm{C}$ at $850 \mathrm{hPa}$ (red), and no statistically significant change at 925 and $700 \mathrm{hPa}$ (green and cyan, respectively). Atmospheric sounding data at the Manaus station in the Amazon (http://weather. uwyo.edu/upperair/sounding.html, station number 82332), translates the AIRS pressure levels of 1000, 925, 850, and $700 \mathrm{hPa}$ to altitudes $(H)$ of $\sim 110 \mathrm{~m}, \sim 800 \mathrm{~m}, \sim 1500 \mathrm{~m}$, and $\sim 3200 \mathrm{~m}$, respectively. The difference between the curves at 1000 and $850 \mathrm{hPa}$ can serve as a good measure for the stability of the lower atmosphere. The temperature difference between 1000 to $850 \mathrm{hPa}(\Delta H \sim 1400 \mathrm{~m})$ along the dry adiabatic lapse-rate is $\sim 14^{\circ} \mathrm{C}$. While the average temperature difference for the clean atmosphere $(\mathrm{AOD} \sim 0.03$, solid arrow, Fig. 3) is $\sim 18.2^{\circ} \mathrm{C}$, suggesting a non stable atmosphere, the average temperature difference for the polluted cases (AOD $\sim 0.55$, dashed arrow, Fig. 3 ) is only $\sim 12.7^{\circ} \mathrm{C}$ indicating a clear shift toward stable atmosphere. Thus, higher values of AOD are associated with a more stable atmosphere at $850 \mathrm{hPa}$ and below as seen visually by the convergence of the curves at 1000 and $850 \mathrm{hPa}$.

We note that a temperature difference of $\sim 18^{\circ} \mathrm{C}$ between $1000 \mathrm{hPa}$ and $850 \mathrm{hPa}$ seems too large, since convection is expected to be an efficient agent in restoring neutral stability. However, the "surface contamination" is not expected to be AOD-dependent (although there is no direct evidence for this), so at most the $1000 \mathrm{hPa}$ curve will be shifted downwards but the trend will stay more-or-less the same. We do note that an instantaneous measurement of the temperature at 13:30 could be unstable.

In addition, the mean temperature difference between the surface and $850 \mathrm{hPa}$ over all AOD values (between 0 and 0.6 ) is $\sim 15^{\circ} \mathrm{C}$. Although some uncertainties might exist in the temperature retrievals, especially near the surface where local temperature gradients might be large, these biases are not expected to be correlated with AOD, as explained above. 

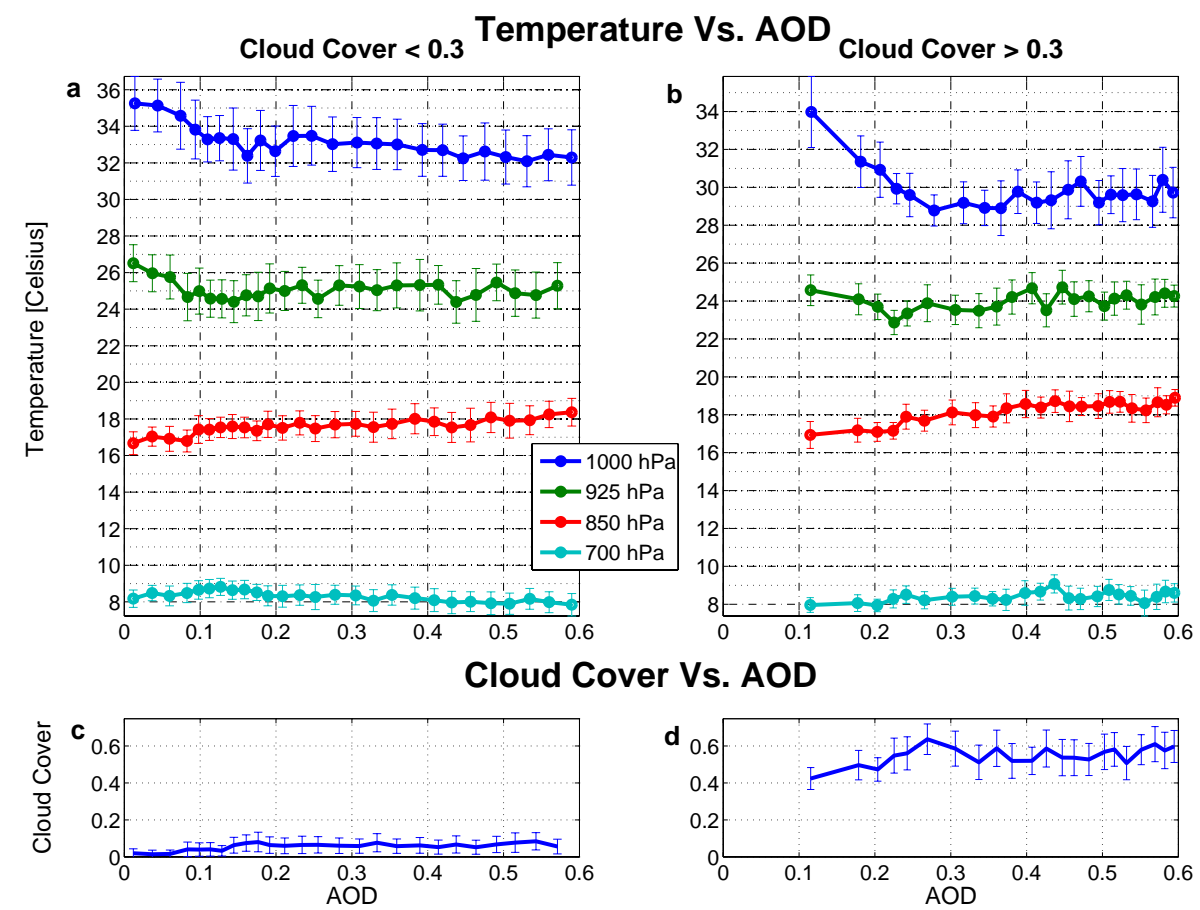

Fig. 4. (a) The same as Fig. 3, but for CC (cloud cover) below 0.3; (b) for CC above 0.3; (c) change in CC as a function of AOD, for $\mathrm{CC}<0.3$; (d) change in $\mathrm{CC}$ as a function of AOD, for $\mathrm{CC}>0.3$. Note the strong cooling near the surface (1000 hPa, blue) in the high cloud cover case (b), compared with the mild, linear cooling in the low cloud cover case (a). The heating at $850 \mathrm{hPa}$ is similar between the two cases.

What portion of the temperature change is directly due to the interaction of the smoke with the solar radiation and what is the contribution of the feedback of the smoke changes of the cloudiness? Koren et al. (2008) suggested that the cloud cover correlates logarithmically with the aerosols optical depth (AOD). These correlations are driven by the microphysical effects of aerosols on clouds. When there are few aerosol particles and AOD is low, small changes in the number of aerosols acting as cloud condensation nuclei (CCN) or ice nuclei (IN) can dramatically change the cloud properties (fraction, vertical development, reflectivity; e.g. Feingold et al., 2001; Kaufman et al., 2005; Koren et al., 2005). However, the microphysical effects tend to saturate, meaning that additional particles will not change the cloud properties in cases where the $\mathrm{CCN}$ concentrations are high $(\sim 1000$ per $\mathrm{cm}^{3}$ ). The saturation of the microphysical effect was shown to occur at $\mathrm{AOD} \sim 0.25$ for the Amazonian smoke (Koren et al., 2008).

Both aerosol direct heating/cooling and indirect heating/cooling from aerosol-induced changes to cloud cover are inherently bundled together into Fig. 3. In order to differentiate between aerosol direct heating/cooling of the atmosphere from aerosol-induced cloud cover effects, we repeated Fig. 3, but divided the data into two classes according to the cloud cover $(\mathrm{CC})$ values: low cloud cover $(\mathrm{CC}<0.3)$ and high cloud cover $(\mathrm{CC}>0.3)$; this is shown in Fig. $4 \mathrm{a}$ and $\mathrm{b}$, respectively.
In low cloud cover (CC) skies $(\mathrm{CC}<0.3$, Fig. $4 a)$, we see a rise in temperature at $850 \mathrm{hPa}$ similar to that in Fig. 3; however, at $1000 \mathrm{hPa}$ the temperature decrease is reduced to $\sim 2.5^{\circ} \mathrm{C}$, compared with $\sim 4^{\circ} \mathrm{C}$ in Fig. 3. In high cloud cover (CC $>0.3$, Fig. 4b), the overall pattern is similar to the low $\mathrm{CC}$ case, but at $1000 \mathrm{hPa}$ (blue) we see a rapid decrease of $\sim 5^{\circ} \mathrm{C}$ as the AOD values reaches $\sim 0.27$, and then a very mild increase (although not significant with respect to the error bars) of the temperature as AOD values rise beyond 0.27 . The heating at $850 \mathrm{hPa}$ in both cases (red curves, Fig. 4a and b) looks similar to the heating in Fig. 3. A more detailed discussion about the heating at $850 \mathrm{hPa}$ will be in the discussion section.

In order to further explore a possible microphysical effect of these aerosols on clouds, we plot the change in the cloud cover as a function of AOD for the two data groups. In low cloud cover case (Fig. 4c), the AOD has a mild effect on the cloud cover, while in the high cloud cover case (Fig. 4d) there is a noticeable increase in cloud cover as AOD reaches a value of $\sim 0.27$ and then no significant change.

To further explore whether the apparent aerosol-induced changes to the temperature profile are related to the direct/heating cooling of the aerosol particles, we need to confirm whether the aerosol layer corresponds to the altitudes where we see the temperature profile change. CALIPSO backscatter data were used (Thomason et al., 2007) to estimate the smoke layer altitude. Figure 5a shows 

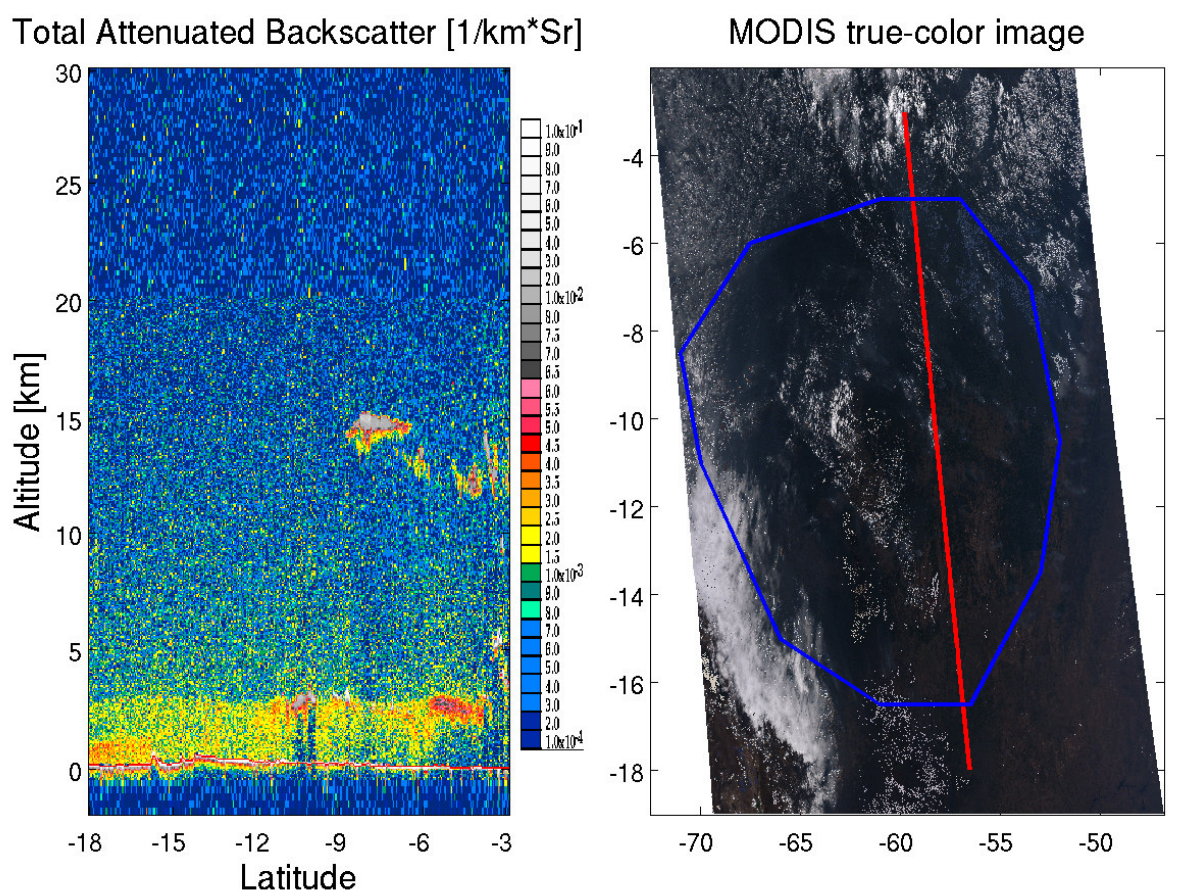

Fig. 5. (a) Calipso image of total attenuated backscatter at $532 \mathrm{~nm}$ (date: 17/8/2007, time: 17:24:18); (b) True color image from MODIS on Aqua, red - Calipso's route, blue - region studied (Fig. 1). These images are characteristic, chosen from 16 images spanning the 2 months period (August-September) analyzed in this work. The smoke top reaches an altitude of about $3.3 \mathrm{~km}$ above ground.

a characteristic CALIPSO total attenuated backscatter at $532 \mathrm{~nm}$ image over the Amazon basin (from date: 17/8/2007, time: 17:24:18). We distinguish smoke from cloud by the fact that smoke is more homogeneous and with lower optical density compared with clouds. A true color image from MODIS is shown in Fig. 5b, which helps identify smoke and clouds in the CALIPSO image. The smoke layer extends from the ground to an altitude of about $3.3 \mathrm{~km}$. These images are characteristic, chosen from 16 images spanning the 2 months period (August-September) analyzed in this work. Examination of these 16 CALIPSO images shows that the smoke reaches an altitude of $3.4 \pm 0.2 \mathrm{~km}$. However, CALIPSO does not provide the distribution of the smoke concentration within the layer. The combination of the CALIPSO lidar and the Manaus sounding data indicate that that the 4 AIRS pressure levels of Figs. 3 and 4 fall within the observed smoke layer, with the $700 \mathrm{hPa}$ at the very top of the smoke.

\section{Discussion}

Figures 3 and 4 present a compelling association between increasing aerosol optical depth in the Amazon and measurable temperature changes within the lower atmosphere. While the altitudes exhibiting the temperature changes lie within the characteristic smoke layer, as observed by CALIPSO, the temperature changes cannot be due solely to heating/cooling by the aerosol absorption and scattering. The cooling due to aerosol extinction of solar radiation in the surface layer is expected to be on the order of $1-2^{\circ} \mathrm{C}$ as shown by $\mathrm{Yu}$ et al. (2002) and Koren et al. (2004) from radiative transfer modeling. Here the observational analysis shows a cooling of $\sim 4^{\circ} \mathrm{C}$, about twice the theoretical values, suggesting that another factor must come into play. By controlling for cloud cover (Fig. 4), thus lessening the cloud contribution, we see that the magnitude of the cooling near the surface is cut in about half. In addition, in the high cloud cover case, saturation appears at AOD 0.27 (Fig. 4b), which agrees with the saturation of the cloud cover at AOD above $\sim 0.27$ (Fig. 4d), while in the low cloud case, the temperature decrease is a linear function of AOD with no saturation point. Repeating the same analysis for different cloud cover cutoff values (i.e. different from 0.3) gave similar results. Ideally we would like to further narrow the cloud cover ranges, but the sample sizes in the narrow ranges became too sparse for statistical analysis.

The temperature rise at $850 \mathrm{hPa}$ is primarily a result of the absorption of solar radiation by the biomass burning aerosols at this level. The magnitude of increase of $\sim 1^{\circ} \mathrm{C}$ is consistent with expectations of $1-2^{\circ} \mathrm{C}$ formed from radiative transfer modeling (Yu et al., 2002; Koren et al., 2004) and there is a steady rise in temperature as AOD increases. Do clouds interfere with this absorption? On partly cloudy days, the absorption might be enhanced due to increased scattering from 
Time Series, Area Statistics

(Region: 69W-53W, 16S-5S)

Aerosol Optical Depth at $550 \mathrm{~nm}$ (MYD08_D3.005)

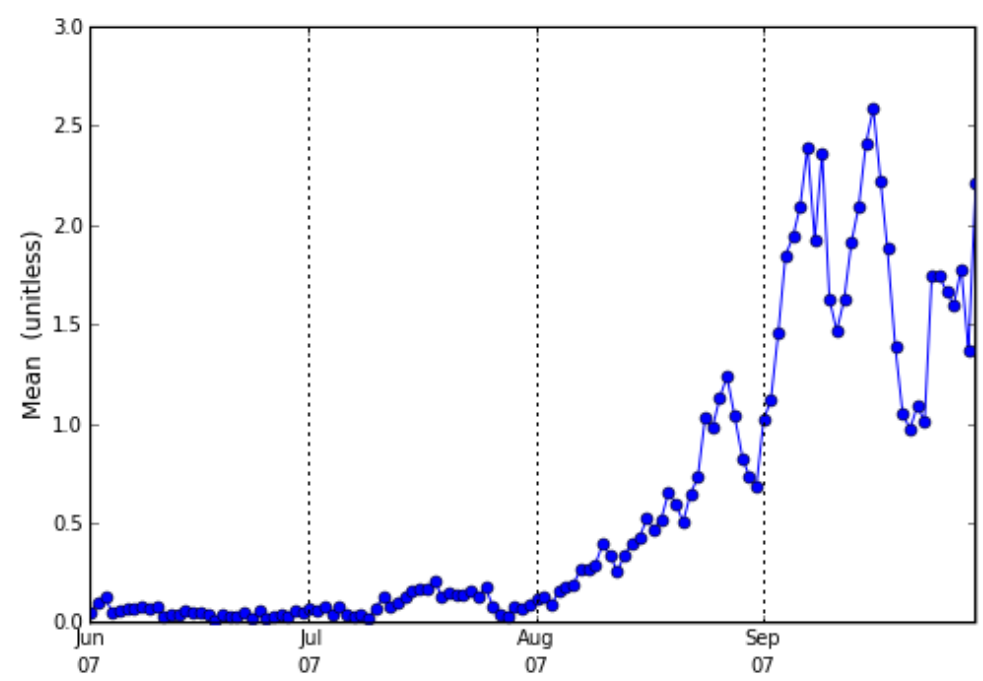

Fig. 6. Mean AOD for the area of interest (Fig. 1) for the months June-September. The burning season clearly starts on August. The Analyses and visualizations used in this figure were produced with the Giovanni online data system, developed and maintained by the NASA Goddard Earth Sciences (GES) Data and Information Services Center (DISC).

clouds (termed 3-D effect; see Wen et al., 2006). On the other hand, clouds could also shed the aerosols below them, thus diminishing the absorption. From Fig. 6, there seems to be no difference in temperature increase at $850 \mathrm{hPa}$ with increasing AOD for the two cloud cover categories, implying that the chance of absorption is the same with and without clouds. However, due to the large variablity of the data (as depicted by the error bars), we cannot determine the role clouds play in the absorption.

The saturation point at AOD $\sim 0.27$ for high cloud cover (Fig. 4b) corresponds to the point at which the aerosol effects on cloud cover switch from primarily the microphysical pathway to the radiative pathway (Koren et al., 2008). In a very pristine atmosphere, addition of aerosol in the form of cloud condensation nuclei (CCN) introduces substantial changes to the cloud microphysics. More numerous but smaller droplets form, and this affects cloud extent and lifetime. The result is a rapid increase of cloud cover as AOD increases from near zero to around 0.25 (Koren et al., 2008). At that point the microphysical pathway reaches a saturation point. Additional CCN do not further increase cloud cover, and instead the radiative pathway becomes dominant.

The fact there is a transition in clouds properties at a certain AOD level was shown previously by both observation (Breon et al., 2002) and modeling (Wang, 2005). Jiang and Feingold (2006), another modeling study showed that this transition point occurs when both microphysical and radiative processes are included in the model, but not when the radiative processes are shut off. Koren et al. (2008) developed
Table 1. A summary for the years 2005-2008. Temperature difference between hazy and clean conditions (i.e. from AOD values of almost 0.6 to nearly zero) within pressure levels 1000 and $850 \mathrm{hPa}$. Positive numbers correspond to heating, negative to cooling. The standard deviation in all years is similar to those presented here for 2007.

\begin{tabular}{ccc}
\hline Year & $\begin{array}{c}\text { Temperature difference between hazy and clean conditions }\left({ }^{\circ} \mathrm{C}\right) \\
1000 \mathrm{hPa}\end{array}$ & $850 \mathrm{hPa}$ \\
\hline 2005 & -5 & 2.5 \\
2006 & -6 & 1 \\
2007 & -4 & 1.5 \\
2008 & -5.5 & 1 \\
\hline
\end{tabular}

an analytical model that describes this transition point at AOD 0.25, and supported this model by observations over the Amazon. Another work of interest on this topic is Rosenfeld et al. (2008). A full discussion of this transition is outside the scope of this paper, and will be addressed in the future.

The pressure level $925 \mathrm{hPa}$ can be viewed as a transition altitude. Its specific response would be determined by the vertical distribution of the smoke, which we cannot know at the moment. On the other hand, the $700 \mathrm{hPa}$ level is at the very top of the smoke layer (Fig. 5), where the smoke is concentrated very thinly. Because the very top of the smoke layer is heated less, this pressure level is expected to be less affected by changes in the smoke loading. 


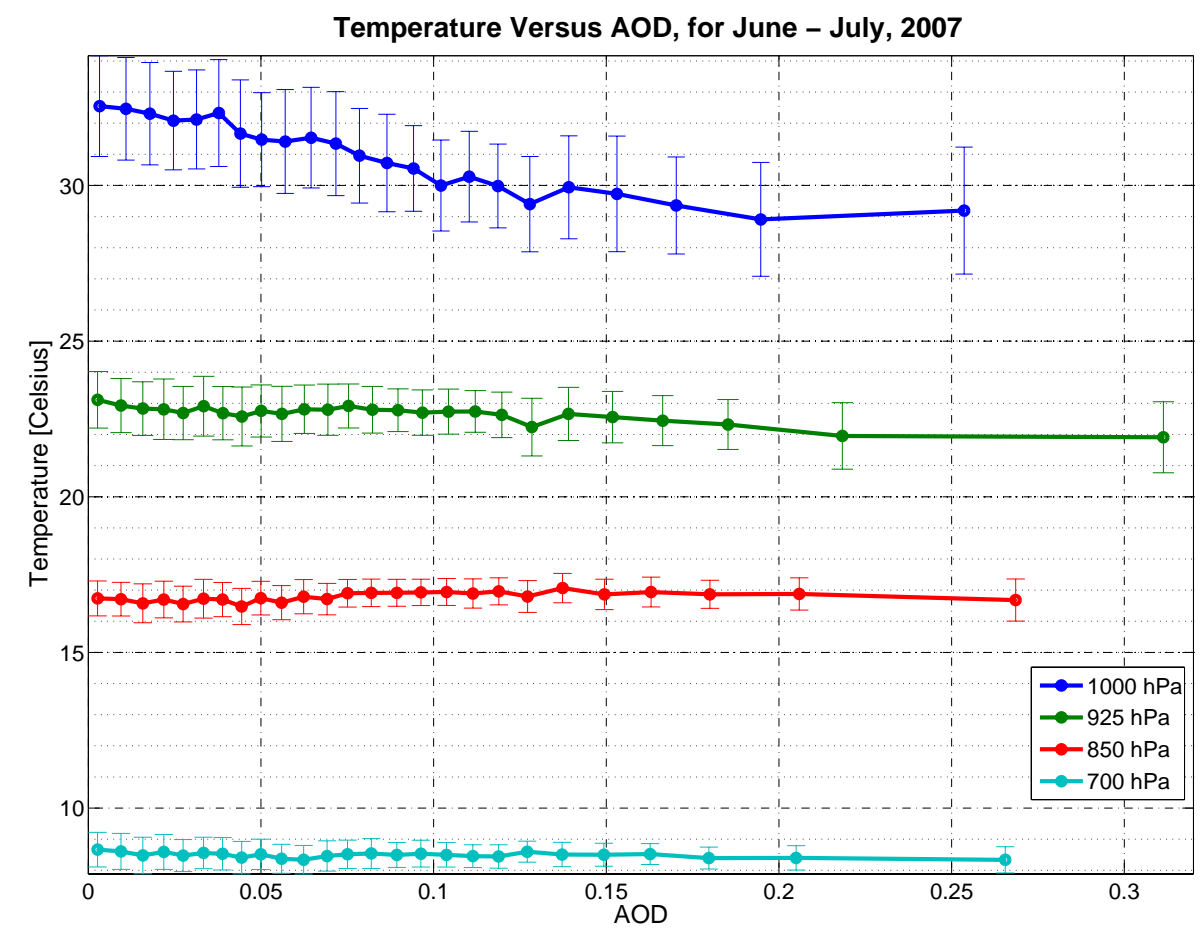

Fig. 7. The same as Fig. 3, but for the months June-July. Note there is no apparent temperature change at $850 \mathrm{hPa}$ pressure level (red curve). The cooling near the surface $(1000 \mathrm{hPa}$, blue curve) is similar to the cooling observed for the months August-September (Fig. 3).

The relationship between temperature and AOD of the 4 pressure levels taken as a whole (Fig. 3) shows clearly the stabilizing effect of the smoke on the lower atmosphere. The temperature difference $(\delta T)$ between the lowest atmospheric layer at $1000 \mathrm{hPa}$ and the $850 \mathrm{hPa}$ layer, $\delta T \equiv T(1000 \mathrm{hPa})-T(850 \mathrm{hPa})$, can serve as an indication of the stability of the atmosphere. The dry adiabatic lapse rate $\left(\Gamma_{\text {dry }}\right)$ is $\sim 1^{\circ} \mathrm{C} / 100 \mathrm{~m}$, and therefore yields a dry adiabatic temperature change between the 2 pressure levels of $\delta T_{\mathrm{dry}}=\Gamma_{\mathrm{dry}} \times \Delta H \approx 14^{\circ} \mathrm{C}$. Figure 3 shows that for the clean atmosphere $(\mathrm{AOD}<0.1) \delta T \sim 18.2^{\circ} \mathrm{C}>\delta T_{\text {dry }}$, suggesting an unstable atmosphere, but for the more hazy cases (AOD $>0.5$ ) $\delta T \sim 12.7^{\circ} \mathrm{C}<\delta T_{\text {dry }}$, suggesting a transition to a stable atmosphere. This stabilization is partly due to the direct interaction of the smoke with the solar radiation and partly due to the feedback in which smoke increases cloud cover. Thus, the microphysical pathway in which aerosol particles increase cloud cover is self-limiting: more clouds lead to a more stable atmosphere, which will eventually reduce cloudiness.

We note that an implicit assumption in the above discussion is that aerosol optical properties vary less than aerosol loading. However, this can be seen in AERONET retrievals beginning with the SCAR-B experiment (Dubovik et al., 1998) and subsequent years (Dubovik et al., 2002).

We have done the same analysis also for the years 2005 , 2006, and 2008. Table 1 summarizes the results for all the years for unrestricted cloud cover (i.e. for 2007, the numbers correspond to Fig. 3). Small differences are expected due to interannual variation in meteorological conditions and biomass burning policies. The response to cloud cover restrictions is similar for all the years, as it was for 2007 and shown in Fig. 4.

Could the correlation between the atmospheric stability and AOD be due to a third agent, namely meteorology? The fires during the Amazonian dry season are anthropogenic and their location depends on the farmers, the farm location and on law enforcement. Therefore the source distribution does not depend on the regional meteorology. Nevertheless, the null hypothesis should be that atmospheric stability favors the formation of aerosols, which results in the correlation seen in Fig. 3. Under the null hypothesis, performing the same analysis - a scatter plot of the temperature versus AOD - with a much less absorbing aerosols, should give the same results as seen in Fig. 3. During the months June-July (the beginning of the dry season), the meteorology is stable and similar to the months August-September, however since the biomass-burning starts only on August (Fig. 6), the aerosols are mostly biogenic, which absorb solar radiation much less (Schafer et al., 2008). Figure 7 shows the same scatter plot, but for the months June-July. During these months, the cooling near the surface $(1000 \mathrm{hPa})$ during June-July is similar to the cooling during August-September. However, there is no heating at $850 \mathrm{hPa}$, compared to the months AugustSeptember, which is in contrast with the null hypothesis. 
Moreover, stable conditions are known to inhibit convective clouds, which are the dominant cloud type in the region studied in this work. Therefore, observing an increase in cloud fraction as AOD increases, despite the increased stability of the lower atmosphere, could indicate that the microphysical effect of aerosol on clouds is the dominant one at low AODs, while at higher AODs the radiative effect become more important, as was suggested and shown by Koren et al. (2008).

Although we cannot completely rule out the possibility that the cooling near the ground in June-July does not have meteorological component. Increased AOD could be due to more stable meteorological conditions that would favor the formation and concentration of particles. Using the tools exploited in this work, it is hard to unravel causality in the temperature trend near the surface. However, there is strong evidence that the heating at $850 \mathrm{hPa}$ is primarily due to aerosol absorption.

Freitas et al. (2005) claimed from modeling results that: "...the presence of the smoke in the atmosphere results in a strong radiative forcing as these particles are very efficient solar radiation scatterers and absorbers. The atmosphere responds to this forcing through a cooling of the low levels and a heating of the upper levels of the PBL (planetary boundary layer). The net effect is an increase in the atmospheric thermodynamical stabilization". This claim is in agreement with our observationally-based arguments.

In this paper we showed - for the first time using observations - the dependence of the Amazonian atmospheric temperature profile on AOD and the effect of cloud cover on this dependence. The direct interaction of the smoke with the solar radiation and the "smoke-increasing cloud fraction" process are coupled and both affect the temperature profile. To decouple these processes, as a first approximation we restricted the data to 2 cloud cover ranges. By restricting cloud cover, the variance can be more easily assigned to each of the two pathways: the microphysical and the radiative. However, it must be acknowledged that the microphysical effect is not completely eliminated, and some of the trends shown in the restricted subsets can be due to the aerosol effect on clouds. Moreover, in addition to the coupling between clouds, aerosol and radiation demonstrated here, the relationships between atmospheric temperature profile and AOD also include components that link atmospheric temperature responses to surface and biospheric processes, and to largescale meteorology. Our analysis provides evidence for a significant contributions by aerosols to these processes, which is superimposed on the meteorological effects. The analysis presented here makes the argument, at the very least, plausible. Illustration of the more complicated picture requires tools beyond those employed in this study.
Acknowledgements. This paper is dedicated to the memory of Yoram J. Kaufman, a dear friend and a brilliant scientist. This research was supported by the Israel Science Foundation (grant no. 1355/06), the Minerva Foundation and NASA's Interdisciplinary Science Program under the direction of H. Maring. I. K. is the incumbent of the Benjamin H. Swig and Jack D. Weiler career development chair at the Weizmann Institute.

Edited by: Y. Rudich

\section{References}

Ackerman, A. S., Toon, O. B., Stevens, D. E., Heymsfield, A. J., Ramanathan, V., and Welton, E. J.: Reduction of tropical cloudiness by soot, Science, 288, 1042-1047, 2000.

Albrecht, B. A.: Aerosols, cloud microphysics, and fractional cloudiness, Science, 245(4923), 1227-1230, 1989.

Andreae, M. O., Artaxo, P., Brandao, C., Carswell, F. E., Ciccioli, P., da Costa, A. L., Culf, A. D., Esteves, J. L., Gash, J. H. C., Grace, J., Kabat, P., Lelieveld, J., Malhi, Y., Manzi, A. O., Meixner, F. X., Nobre, A. D., Nobre, C., Ruivo, M. D. L. P., Silva-Dias, M. A., Stefani, P., Valentini, R., von Jouanne, J., and Waterloo, M. J.: Biogeochemical cycling of carbon, water, energy, trace gases, and aerosols in Amazonia: The LBAEUSTACH experiments, J. Geophys. Res., 107(D20), 8066, doi:10.1029/2001JD000524, 2002.

Andreae, M. O. and Rosenfeld, D.: Aerosol-cloud-precipitation interactions. Part 1, The nature and sources of cloud-active aerosols, Earth Sci. Rev., 89, 13-41, 2008.

Aumann, H. H., Chahine, M. T., Gautier, C., Goldberg, M. D., Kalnay, E., McMillin, L. M., Revercomb, H., Rosenkranz, P. W., Smith, W. L., Staelin, D. H., Strow, L. L., and Susskind, J.: AIRS/AMSU/HSB on the Aqua mission: Design, science objectives, data products, and processing systems, IEEE T. Geosci. Remote, 41(2), 253-264, 2003.

Brennan, J. I., Kaufman, Y. J., Koren, I., and Li, R. R.: Aerosolcloud interaction - misclassification of MODIS clouds in heavy aerosol, IEEE T. Geosci. Remote, 43(4), 911-915, 2005.

Breon, F. M., Tanre, D., and Generoso, S.: Aerosol effect on cloud droplet size monitored from satellite, Science, 295(5556), 834838, 2002.

de Souza, R. A. F., Ceballos, J. C., and Barnet, C. D.: Performance of the aqua/nasa and noaa-16/ici soundings over rondonia during the dry-to-wet lba experiment, The 14th international TOVS study conference, Beijing, China, May, 2005.

de Souza, R. A. F., Rodrigues, J. V., and Ceballos, J. C.: Performance of the aqua/nasa and modis soundings over natal/brazil using collocated sondes: Shadoz campain 2004-2005, The 15th international TOVS study conference, Maratea, Italy, October, 2006.

Dubovik, O., Holben, B., Eck, T. F., Smirnov, A., Kaufman, Y. J., King, M. D., Tanre, D., and Slutsker, I.: Variability of absorption and optical properties of key aerosol types observed in worldwide locations, J. Atmos. Sci., 59, 590-608, 2002.

Dubovik, O., Holben, B. N., Kaufman, Y. J., Yamasoe, M., Smirnov, A., Tanre, D., and Slutsker, I.: Single-scattering albedo of smoke retrieved from the sky radiance and solar transmittance measured from ground, J. Geophys. Res., 103, 31903-31923, 1998. 
Feingold, G., Jiang, H., and Harrington, J. Y.: On smoke suppression of clouds in Amazonia, J. Geophys. Res., 32, L02804, doi:10.1029/2004GL021369, 2005.

Feingold, G., Remer, L. A., Ramaprasad, J., and Kaufman, Y. J.: Analysis of smoke impact on clouds in Brazilian biomass burning regions: An extension of Twomey's approach, J. Geophys. Res., 106, 22907-22922, 2001.

Forster, P., Ramaswam, V., Artaxo, P., Berntsen, T., Betts, R., Fahey, D., Haywood, J., Lean, J., Lowe, D., Myhre, G., Nganga, J., Prinn, R., Raga, G., Schulz, M., and Van Dorland, R.: Changes in atmospheric constituents and in radiative forcing, edited by: Solomon, S., Qin, D., Manning, M., Chen, Z., Marquis, M., Averyt, K., Tignor, M., in: Climate Change 2007: The Physical Science Basis, Contribution of Working Group I to the Fourth Assessment Report of the Intergovernmental Panel on Climate Change, Cambridge University Press, Cambridge, UK and New York, NY, USA, 2007.

Freitas, S. R., Longo, K. M., Chatfield, R., Latham, D., Silva Dias, M. A. F., Andreae, M. O., Prins, E., Santos, J. C., Gielow, R., and Carvalho Jr., J. A.: Including the sub-grid scale plume rise of vegetation fires in low resolution atmospheric transport models, Atmos. Chem. Phys., 7, 3385-3398, 2007, http://www.atmos-chem-phys.net/7/3385/2007/.

Freitas, S. R., Longo, K. M., Silva Dias, M. A. F., Silva Dias, P. L., Chatfield, R., Prins, E., Artaxo, P., Grell, G. A., and Recuero, F. S.: Monitoring the transport of biomass burning emissions in South America, Environ. Fluid Mech., 5(1-2), 135-167, 2005.

Gao, W. H., Zhao, F. S., Xu, Y. F., and Feng, X.: Validation of the surface air temperature products retrieved from the atmospheric infrared sounder over china, IEEE T. Geosci. Remote, 46(6), 1783-1789, 2008.

Hansen, J., Sato, M., and Ruedy, R.: Radiative forcing and climate response, J. Geophys. Res., 102, 6831-6864, 1997.

Jiang, H. and Feingold, G.: Effect of aerosol on warm convective clouds: Aerosol-cloud-surface flux feedbacks in a new coupled large eddy model, J. Geophys. Res., 111, D01202, doi:10.1029/2005JD006135, 2006.

Kaufman, Y. J., Koren, I., Remer, L. A., Rosenfeld, D., and Rudich, Y.: The effect of smoke, dust, and pollution aerosol on shallow cloud development over the Atlantic Ocean, P. Natl. Acad. Sci. USA, 102, 11207-11212, 2005.

Kaufman, Y. J. and Koren, I.: Smoke and pollution aerosol effect on cloud cover, Science, 313, 355-658, 2006.

Koren, I., Kaufman, Y. J., Remer, L. A., and Martins, J. V.: Measurement of the effect of Amazon smoke on inhibition of cloud formation, Science, 303, 1342-1345, 2004.

Koren, I., Kaufman, Y. J., Resonfeld, D., Remer, L. A., and Rudich, Y.: Aerosol invigoration and restructuring of Alantic convctive clouds, Geophys. Res. Lett., 32, L14828, doi:10.1029/2005GL023187, 2005.

Koren, I., Martins, J. V., Remer, L. A., and Afargan, H.: Smoke invigoration versus inhibition of clouds over the Amazon, Science, 321, 946-949, 2008.

Levy, R. C., Remer, L. A., Mattoo, S., Vermote, E. F., and Kaufman, Y. J.: Second-generation operational algorithm: Retrieval of aerosol properties over land from inversion of Moderate Resolution Imaging Spectroradiometer spectral reflectance, J. Geophys. Res., 112, D13211, doi:10.1029/2006JD007811,2007.

Lohmann, U. and Feichter, J.: Global indirect aerosol effects: a review, Atmos. Chem. Phys., 5, 715-737, 2005, http://www.atmos-chem-phys.net/5/715/2005/.

Nobre, C. A., Mattos, L. F., Dereczynski, C. P., Teresova, T. A., and Trosnikov, I. V.: Overview of atmospheric conditions during the Smoke, Clouds, and Radiatio - Brazil (SCAR-B) field experiment, J. Geophys. Res., 103, 31809-31820, 1998.

Olsen, E. T., Fetzer, E., Lee, S.-Y., Manning, E., Blaisdell, J., and Susskind, J.: AIRS/AMSU/HSB version 5 CalVal status summary, available at: http://disc.gsfc.nasa.gov/AIRS/ documentation, last access: 4 March 2009, 2007.

Reale, O., Susskind, J., Rosenberg, R., Brin, E., Liu, E., Riishojgaard, L. P., Terry, J., and Jusem, J. C.: Improving forecast skill by assimilation of quality-controlled AIRS temperature retrievals under partially cloudy conditions, Geophys. Res. Lett., 35, L08809, doi:10.1029/2007GL03302, 2008.

Remer, L. A., Kleidman, R. G., Levy, R. C., Kaufman, Y. J., Tanre, D., Mattoo, S., Martins, J. V., Ichoku, C., Koren, I., $\mathrm{Yu}, \mathrm{H}$., and Holben, B. N.: Global aerosol climatology from the MODIS satellite sensors, J. Geophys. Res., 113, D14S07, doi:10.1029/2007JD009661, 2008.

Rosenfeld, D.: Suppression of rain and snow by urban and industrial air pollution, Science, 287, 1793-1796, 2000.

Rosenfeld, D., Lohmann, U., Raga, G. B., O’Dowd, C. D., Kulmala, M., Fuzzi, S., Reissell, A., and Andreae, M. O.: Flood or Drought: How Do Aerosols Affect Precipitation?, Science, 321, 1309-1313, 2008.

Salati, E.: The forest and the hydrological cycle, edited by: Dickinson, R. E., in: Geophysiology of Amazonia, John Wiley \& Sons, New York, 273-296, 1987.

Schafer, J. S., Eck, T. F., Holben, B. N., Artaxo, P., and Duarte, A. F.: Characterization of the optical properties of atmospheric aerosols in Amazonia from long-term AERONET monitoring (1993-1995 and 1999-2006), J. Geophys., Res., 113, D04204, doi:10.1029/2007JD009319, 2008.

Susskind, J., Barnet, C., Blaisdell, J., Iredell, L., Keita, F., Kouvaris, L., Molnar, G., and Chahine, M.: Accuracy of geophysical parameters derived from atmospheric infrared sounder/advanced microwave sounding unit as a function of fractional cloud cover, J. Geophys. Res., 111(D9), D09S17, doi:10.1029/2005JD006272, 2006.

Stevens, B. and Feingold, G.: Untangling aerosol effects on clouds and precipitation in a buffered system, Nature, 461, 607-613, 2009.

Teller, A. and Levin, Z.: The effects of aerosols on precipitation and dimensions of subtropical clouds: a sensitivity study using a numerical cloud model, Atmos. Chem. Phys., 6, 67-80, 2006 , http://www.atmos-chem-phys.net/6/67/2006/

Tobin, D. C., Revercomb, H. E., Knuteson, R. O., Lesht, B. M., Strow, L. L., Hannon, S. E., Feltz, W. F., Moy, L. A., Fetzer, E. J., and Cress, T. S.: Atmospheric Radiation Measurement site atmospheric state best estimates for Atmospheric Infrared Sounder temperature and water vapor retrieval validation, J. Geophys. Res., 111, D09S14, doi:10.1029/2005JD006103, 2006.

Thomason, L. W., Pitts, M. C., and Winker, D. M.: CALIPSO observations of stratospheric aerosols: a preliminary assessment, Atmos. Chem. Phys., 7, 5283-5290, 2007, http://www.atmos-chem-phys.net/7/5283/2007/.

Twomey, S.: The influence of pollution on the shortwave albedo of clouds, J. Atmos. Sci., 34, 1149-1152, 1977. 
Wang, C.: A modeling study of the response of tropical deep convection to the increase of cloud condensation nuclei concentration: 1, Dynamics and microphysics, J. Geophys. Res., 110(D21), D21211, doi:10.1029/2004JD005720, 2005.

Wen, G., Marshak, A., and Cahalan, R. F.: Impact of 3-D Clouds on Clear-Sky Reflectance and Aerosol Retrieval in a Biomass Burning Region of Brazil, IEEE T. Geosci. Remote, 3(1), 169$172,2006$.
Winker, D. M., Pelon, J., and McCormick, M. P.: The CALIPSO mission: Space borne lidar for observation of aerosols and clouds, Proc. SPIE, 4893, 1-11, 2003.

Yu, H. B., Liu, S. C., and Dickinson, R. E.: Radiative effects of aerosols on the evolution of the atmospheric boundary layer, J. Geophys. Res., 107(D12), 4142, doi:10.1029/2001JD000754, 2002. 